\title{
An Investigation of the Mechanisms for Strength Gain or Loss of Geopolymer Mortar after Exposure to Elevated Temperature
}

\author{
Zhu Pan ·Jay G. Sanjayan 'B.V. Rangan \\ Zhu Pan, Jay G. Sanjayan* \\ Department of Civil Engineering, Monash University, Clayton, VIC 3800, Australia \\ e-mail: jay.sanjayan@eng.monash.edu.au \\ B.V. Rangan \\ Curtin University of Technology, Perth, WA, Australia
}

\begin{abstract}
:
When fly ash based geopolymer mortars were exposed to a temperature of $800^{\circ} \mathrm{C}$, it was found that the strength after the exposure sometimes decreased, but at other times increased. This paper shows that ductility of the mortars has a major correlation to this strength gain/loss behaviour. Specimens prepared with two different fly ashes, with strengths ranging from 5 to $60 \mathrm{MPa}$, were investigated. Results indicate that the strength losses decrease with increasing ductility, with even strength gains at high levels of ductility. This correlation is attributed to the fact that mortars with high ductility have high capacity to accommodate thermal incompatibilities. It is believed that the two opposing processes occur in mortars: (1) further geopolymerisation and/or sintering at elevated temperatures leading to strength gain; (2) the damage to the mortar because of thermal incompatibility arising from non-uniform temperature distribution. The strength gain or loss occurs depending on the dominant process.
\end{abstract}

Keywords Geopolymer; Mortar; Strength; Elevated Temperature; Ductility 


\section{Introduction:}

Geopolymers are ceramic-like materials that are produced by reaction of aluminosilicate raw materials in alkaline environments and hydrothermal conditions [1]. They belong to the group of ecologically-friendly materials because the production of raw materials for geopolymers requires lower energy consumption, in comparison to Portland cements, which contribute significant levels of carbon-dioxide and is part of the global greenhouse gas problem [2].

In recent years, there has been a growing interest in research activities into manufacture of geopolymers and the resulting properties [3-8]. Rangan and his coworkers [9-12] have carried out extensive research on fly ash-based geopolymer concrete. They [13] reported that concretes could be manufactured by using fly ash in combination with sodium silicate and sodium hydroxide solution. After heat cured at $60^{\circ} \mathrm{C}$ for 24 hours, geopolymer concretes showed optimum engineering properties [14].

While Portland cement based mortars and concretes are generally considered to be fire resistant, the decomposition of $\mathrm{Ca}(\mathrm{OH})_{2}$ around $500^{\circ} \mathrm{C}$ causes significant damage to these materials [15]. Geopolymers are attracting increasing interest as an alternative building material to Portland cement, especially in high temperature applications because of their potentially superior performance at high temperatures.

For Portland cement based materials, it has been recognized that the mechanisms affecting strength at elevated temperatures are (i) thermal incompatibility, (ii) pore pressure effects, and (iii) phase transformations [16]. The majority of published studies on strength performance of geopolymer subjected to elevated temperatures 
have focused on the last two mechanisms: The effects of different raw-materials [17], alkali cations [18] and calcium contents [19] on residual strength have been investigated in some depth. Unlike Portland cement based materials, it was found that sometimes the geopolymer strength increases and other times it decreases after exposure to elevated temperatures $[17,18]$. In previous literature, the contrasting behaviours were only related to the mechanism (ii) [17] or a combination of mechanism (ii) and (iii) [18].

Besides the last two mechanisms that take place in geopolymer, the strength of geopolymer is affected by the thermal incompatibility (mechanism (i)). Thermal incompatibility arises because heat flow in solid bodies takes time to reach steady state, depending on the thermal conductivity and thermal capacity of the material. When the non-uniform thermal deformation cannot be sustained by specimen, the strength degradation occurs due to the initiation and propagation of cracks. Further, the thermal incompatibility in non-homogenous two-phase materials (mortar or concrete) also arises because of different movements between the matrix and the inclusion.

The effect of thermal incompatibility on strength is generally determined by two aspects: (1) severity of thermal incompatibility the specimen suffered at elevated temperatures; (2) extent to which specimens can be deformed without fracture, namely, the ductility of a material. Specimens with high ductility can reduce the effect of thermal incompatibility on strength because of higher tolerance for non-uniform thermal deformation. This provides the explanation that use of various types of fibres in Portland cement based concrete improves the ductility (or reduces brittleness), and 
therefore improves the residual strength of concrete after exposure to elevated temperatures [20-22].

At the first stage of the current investigation, various mixes were conducted on mortars to study the effects of elevated temperature on compressive strength of geopolymeric materials. After exposure to elevated temperatures, mortars with high initial strength experienced strength loss, while mortars with low initial strength improved strength. It is well known that the ductility levels in normal and high strength concretes are generally correlated to the strength, having a relationship of decreasing ductility with increasing strength. The purpose of this investigation is to study whether strength gain or loss after exposure to elevated temperature is influenced by ductility of geopolymer mortars. This paper thus mainly focuses on mechanism (i) (thermal incompatibility) which has received less attention in the geopolymer literature, as compared to Portland cement literature where this aspect has been widely researched.

\section{Experimental Programme:}

Previous studies showed that high temperature performance of geopolymer is significantly influenced by the materials used in the synthesis process. Kong et al. [16, 23] found that the fly ash-based geopolymers have large numbers of small and continuous pores while metakaolinite geopolymers do not possess such pore structures. The difference in microstructure was suggested to be responsible for the observed trends, which indicated that the strength of fly ash based geopolymer increased while the strength of metakaolinite geopolymer decreased after the same thermal exposure. A similar contrasting behaviour is also found in the geopolymer 
prepared by using different alkali cations [17]. This is attributed to fact that geopolymers prepared by using K-containing liquids have better thermal stability than those prepared by using Na-containing liquids. Duxson [24] found that the increase in the soluble silicon content of the alkali liquid plays an important role in thermal evolution of structure of geopolymer. This is believed to be a result of varying the $\mathrm{Si} / \mathrm{Al}$ ratio of geopolymer by dissolution of amorphous silica into the alkaline activating solution.

The authors' believe that the mechanisms of degradation of geopolymer can be categorised the same way as for Portland cement mentioned earlier, i.e., (i) thermal incompatibility, (ii) pore pressure effects, and (iii) phase transformations [16]. To study the effect of mechanism (i), it is important to minimise or eliminate the effects of (ii) and (iii). Following from the previous studies [16-17, 23-24], it is clear that the soluble silicon content in alkaline liquid and alkali cations have significant influence on thermal behaviour and therefore should not be varied between the specimens, so that effect of mechanism (i) can be studied without the interference from these parameters. The authors' have manipulated the sample curing regime to change the resultant strength of geopolymers, without changing the mixture proportions, and therefore, the initial chemical compositions of the geopolymers remain unchanged, except for the two types of fly ashes used.

\section{Materials}

Fly ashes used in the investigation were dry Type F (low-calcium) fly ash. The chemical composition of the fly ashes, as determined by X-ray Fluorescence (XRF) analysis, is given in Table 1. To ensure that the observed trends are not due to the 
peculiarity of one particular fly ash, two very different types of fly ashes were chosen for making geopolymers and analysis of residual mechanical properties.

One of the alkaline solutions used was commercially-available sodium silicate solution A53 with a specific gravity of 1.53 and a modulus ratio (Ms) equal to 2 (where $\mathrm{Ms}=\mathrm{SiO}_{2} / \mathrm{Na}_{2} \mathrm{O}, \mathrm{Na}_{2} \mathrm{O}=14.7 \%$ and $\mathrm{SiO}_{2}=29.4 \%$ by mass). The other alkaline solution used was prepared by dissolving the commercial grade sodium hydroxide $(\mathrm{NaOH})$ pellets with $98 \%$ purity in distilled water. The concentration of the $\mathrm{NaOH}$ solution was 10 Molar. Both the alkaline solutions were mixed together to form the alkaline liquid.

The sand used was locally available river sand. The sand was dried first in an oven, and then wetted until saturated-surface-dry condition was reached.

\section{Specimen preparation}

As mentioned before, the number of variables were kept to a minimum by using the same mixture proportions for all the specimens. The ratio of sand-to-fly ash was 3 . The sodium silicate solution-to-sodium hydroxide solution ratio was fixed at 2.5 . The ratio of alkaline liquid-to-fly ash ratio was 0.605 .

In order to prepare the geopolymer mortar mixtures, a 20 litre capacity mechanical mixer with a rotating speed of $80 \mathrm{rpm}$ was used. For all mixtures, the sand was initially blended with the amount of water calculated to be necessary to bring the sand to saturated-surface-dry condition. This amount of water was mixed with sand for 1 minute to obtain the saturated surface dry condition. The fly ash was then added to the mixture. After 2 minutes of mixing, the alkaline liquid was added to the mixture and 
the mixing continued for an additional 4 minutes. Cylinders of $50 \mathrm{~mm}$ diameter and $100 \mathrm{~mm}$ high were prepared as test specimens. The test specimens were compacted using a vibration table.

\section{Curing Regimes}

The only variable between the specimens is the type of curing regimes administered, as summarized in Table 2. In order to develop various strength levels of specimens, the curing regimes were varied, as determined by trial tests. Within one hour after the specimens were prepared, they were placed in an oven preheated to the specified temperature. Specified temperatures for various specimens are presented in Table 2. Table 2 also presents the length of time each specimen was kept in the oven. Some specimens, denoted by " $\mathrm{S}$ " in Table 2, were kept in the moulds and wrapped by plastic sheet while being cured in the oven. Other specimens, denoted by "W" in Table 2, were kept and wrapped in the same condition, except the moulds were left in a container full of water while cured in the oven.

\section{Elevated temperature exposure regime}

The specimens were subjected to temperatures of up to $800^{\circ} \mathrm{C}$ at an incremental rate of $4.4^{\circ} \mathrm{C}$ per minute from room temperature of $23^{\circ} \mathrm{C}$ in a high temperature furnace. Once the temperature of $800^{\circ} \mathrm{C}$ was attained, it was maintained for further 2 hours. After that, the furnace was switched off and the specimens were allowed to cool naturally in the furnace to room temperature (Fig. 1). To measure temperature gradient, two thermocouples were installed at mid-height of cylinder; one on the center and the other on the surface. 
Tests

All the specimens were load tested in compression. This is a common practice in Portland cement mortars to characterise the material. In Portland cement mortars, the failure in compression is said to be governed by the tension that develops in the material. Therefore, it may be argued that tensile tests are more appropriate. However, it is common practice to carry out compression test to characterise Portland cement mortars and not tensile test, because (1) compression tests are more repeatable and show less scatter; (2) relatively simpler to carry out, and less influenced by operator errors than tensile tests; and (3) compressive and tensile strength of the mortars are closely related. For the same reasons listed above, the compressive tests have been selected for this research on geopolymer mortars.

In order to determine the initial strength of geopolymer mortar prior to exposure to elevated temperature, cylinders were tested at an age of 5 days after casting. After the elevated temperature test, the specimens were tested the next day to determine the residual strength. The specimens were capped with sulphur capping to ensure that the ends of sample are plane. The cylinders were tested at a loading rate of $20 \mathrm{MPa} / \mathrm{min}$. At least 3 samples were used for each data and standard deviation is presented in Figs. 2 and 3.

For generating data in the descending part of the stress-strain curve of mortar, a strain control loading technique was adopted. The load was applied, at a constant displacement rate of $0.017 \mathrm{~mm} / \mathrm{sec}$, using an automated computer controlled system. The load and deformation of the specimens were recorded continuously for the duration of each test. 
The TGA (Thermogravimetric Analysis) was conducted in a TG92-Setaram, with the temperature of the furnace programmed to rise at constant heating rate of $5^{\circ} \mathrm{C} / \mathrm{min}$ up to $800^{\circ} \mathrm{C}$, under air flow.

\section{Results:}

\section{Compressive strength}

Strength results before and after temperature exposures for the mortars prepared using Ashes A and B are summarized in Figs. 2 and 3 respectively. As presented in Figs. 2 and 3, the mortars prepared using both fly ashes showed different tendency (gain or loss) in evolution of strength after exposure to elevated temperature. After exposure to $800^{\circ} \mathrm{C}$, the mortars with initial strength levels up to $16 \mathrm{MPa}$ increased in strength, whilst the others decreased in strength (Figs. 2 and 3). This applies to both the fly ashes used in the current investigation, despite the significant differences $(\mathrm{CaO}$ content, $\mathrm{Fe}_{2} \mathrm{O}_{3}$ content and $\mathrm{Si} / \mathrm{Al}$ ) of the fly ashes (Table 1).

\section{Thermogravimetric Analysis}

The thermogravimetric analysis data of mortars prepared by using Ash B are presented in Fig. 4. All mortars experienced mass loss with the increase of temperature. The maximum mass loss of $8 \%$ after temperature exposures was recorded for the geopolymer mortars, which was significantly lower than that of the Portland cement paste [15] (30\% mass loss). The Portland cement paste showed a noticeable mass loss around $500^{\circ} \mathrm{C}$, which is consistent with the mass loss due to the dehydration of $\mathrm{Ca}(\mathrm{OH})_{2}$ [15]. On the other hand, the majority mass loss of all geopolymer mortars occurred within the first $200^{\circ} \mathrm{C}$ and the mass stabilised after 
approximately $800^{\circ} \mathrm{C}$. This mass loss of geopolymer mortars is assumed to be due to loss of evaporable water.

Densities of geopolymer mortars before and after the elevated temperature exposures are presented in Table 2. A comparison of these densities with TGA results show that change densities are mainly due loss of water. However, exact match cannot be achieved since the mortars also were subjected to shrinkage or expansion.

\section{Ductility}

The ductility of geopolymer mortars was assessed by measuring the stress-strain curves which are presented in Figs. 5 and 6. It can be observed that considerable shape differences exist amongst the strain-stress curves. The geopolymer mortars with lower initial strength demonstrate greater ductility, as evidenced by a rounder shape. On the other hand, geopolymer mortars with higher initial strength have stress-strain curves that fall within a narrow band and exhibit a distinctly different response in the descending part compared to the specimens at lower initial strength. These results suggest that mortar with high initial strength exhibit low ductile characteristics.

To establish the relationship between the ductility and the evolution of strength after exposure to elevated temperature, it is necessary to quantify the ductility of geopolymer mortars. The ductility is defined by two methods, as shown in Fig. 7. One method is to find ductility index by dividing strain $\varepsilon_{2}$ by strain $\varepsilon_{1}$, as used by Toutanji

[25] to assess the ductility of concrete columns. Strain $\varepsilon_{1}$ corresponds to an initial strain corresponding to an approximation of the limit of elasticity behaviour. A best- 
fit line of the linear portion of the stress-strain graph of each mortar was obtained by linear regression analysis. This line was then extrapolated to intersect with the peak stress of the mortars. Strain $\varepsilon_{2}$ corresponds to 0.85 of the peak stress in the descending part. Another method is to define the ductility index by dividing the total energy A at failure by the elastic energy $A_{e}$ stored at peak load.

The relationship between the percentage of strength evolution and ductility of all geopolymer mortar specimens is presented in Figs.8 and 9. The percentage $(\Delta)$ of strength evolution was calculated: $\mathrm{f}_{\mathrm{o}}$-strength before exposure to elevated temperature, $f_{r}$-strength after exposure to elevated temperature and $\Delta=\left(f_{r}-f_{o}\right) / f_{0}$. The level of ductility presented in Figs. 8 and 9 is derived from the strain and energy absorption respectively. It can be seen from both figures that ductility indexes have a strong correlation to the residual strength of geopolymer mortars.

\section{Discussions:}

In addition to $\mathrm{Al}_{2} \mathrm{O}_{3}$ and $\mathrm{SiO}_{2}$, fly ash contains side phases, including sulfates, chlorides, heavy metals, and calcium compounds as main components [19]. Unlike ordinary Portland cement based material, in which the dissociation of $\mathrm{Ca}(\mathrm{OH})_{2}$ followed by rehydration leads to the disintegration of OPC, geopolymer mortar contained no $\mathrm{Ca}(\mathrm{OH})_{2}$ as shown by the TGA study (no peak at $500-600^{\circ} \mathrm{C}$ ) presented in Fig. 3. The minor calcium compounds presented in fly ash may be totally consumed in the formation of calcium silicate hydrate phases, which were found [19, $26]$ to coexist in geopolymeric systems. 
The mass loss of specimen, 55W15, is slightly higher than that of 60S2 and 60S18. This is likely to be due to the high humidity in curing regime of 55W15. It is of interest to note that the mass of all geopolymer mortars is stabilized in the temperature range of $200-800^{\circ} \mathrm{C}$, suggesting that pore pressures cause minimal damage to the matrix as very small amount of free water was escaping above $200^{\circ} \mathrm{C}$. Below $200^{\circ} \mathrm{C}$, previous study [27] suggested that the change in residual strength of geopolymer mortars is very subtle, which is also supported by unreported results from our preliminary tests.

Initial strength is found to be a factor influencing strength gain or loss of geopolymer mortars exposed to elevated temperatures. A similar trend is also reported previously $[18,19]$. The factors reported in previous literature to have influence on the residual strength of geopolymer after elevated temperature exposure are different alkali cations [18] and presence of pure $\mathrm{Ca}(\mathrm{OH})_{2}$-powder in the mixtures [19]. These factors are kept the same between the specimens in the current investigation and therefore, their influence is minimized and/or avoided. Further, the specimens of the current investigation have higher temperature gradient than the previous ones $[18,19]$, since the specimens are larger than the cylinders used by Bakharev [18] and has less surface/volume ratio than the cubes used by Dombrowski [19].

With respect to Portland cement paste, the effect of thermal incompatibility arising from temperature gradient on mechanical properties is well known, and has been experimentally demonstrated by Kristensen and Hansen [28]. In their experiments, pastes, which had been slowly cooled to $0^{\circ} \mathrm{C}$, were instantaneously heated to $20^{\circ} \mathrm{C}$, $30^{\circ} \mathrm{C}, 60^{\circ} \mathrm{C}$ and $80^{\circ} \mathrm{C}$. The magnitude of temperature gradient that is required for 
cracking to occur in cement paste was found to be between $20^{\circ} \mathrm{C}$ and $30^{\circ} \mathrm{C}$ over a 50 mm length. The severity of thermal incompatibility that geopolymer mortars suffered in the current investigation is higher than the ones reported [28] for Portland cement pastes because: (1) the measured temperature difference between center and outside of the geopolymer mortar was about $100^{\circ} \mathrm{C}$ when the temperature of furnace reached $800^{\circ} \mathrm{C}$; (2) geopolymer and Portand cement paste exhibit comparable shrinkage at elevated temperature [23, 29]; (3) geopolymer mortar contains sand in the paste matrix. Therefore, the level of thermal incompatibility experienced by the specimens in the current investigation is significant. The damaging effect of thermal incompatibility in geopolymer concretes has also been demonstrated previously [30].

However, thermal incompatibility by itself does not determine the level of damage caused to the specimens, as the material's ability to accommodate the thermal incompatibility also does play an important role. This ability to accommodate incompatible deformations is characterised by ductility or brittleness of the material. Ductility is shown to have a tendency of decrease with increasing initial strength in Figs.5 and 6. This trend indicates that the relationship between initial strength and strength gain or loss is an essential reflection of relationship between ductility and strength evolution.

Figs. 8 and 9 show the strength of geopolymer mortars, after exposure to elevated temperature, improved when the ductility level is higher than a particular threshold, whilst strength decreased when the ductility was lower than the threshold. The reason for this trend could be explained by the two parallel processes that occurs at elevated temperature in geopolymer mortars: (1) One process is the further geopolymerisation 
of the unreacted fly ash and/or sintering process [17, 19] which result in strength increase; (2) The other process is the damage to the specimen as a result of thermal incompatibility, and this is also a function of the ductility level of the material. These two opposing processes are occurring simultaneously in the geopolymer mortars at elevated temperatures and whether the strength increases or decreases is dependent on the dominant process. Since many of the chemical factors and thermal incompatibility were kept the same, the balance tips to process (1) or process (2) depending on the level of ductility. This effect is reflected by results showing a strong correlation between strength gain/loss and the level of ductility in Figs. 8 and 9.

Fig. 10 schematically demonstrates the two parallel processes ( $1 \& 2$ ) described above. The Process (1), which causes increase in strength due to sintering and/or further geopolymerisation, is always positive, and approximately shown to increase with ductility. This is because high ductile mortars were lower in strength and have more capacity for further increase than low ductile/high strength counterparts. The Process (2) is damage due to thermal incompatibility and is always negative causing strength reduction, but the reduction decreases with increasing ductility. The strength gain or loss observed in the experiments is the combined result of the two parallel processes, also shown in Fig. 10. It should be emphasized that Fig. 10 is only a schematic diagram to describe the view of the authors', and not an accurate representation of the effects of the two processes. 


\section{Conclusions:}

The following conclusions are drawn from the investigation presented in this paper:

(1) Geopolymer mortars (geopolymer + sand) sometimes can increase in strength and other times decrease in strength after exposure to elevated temperature of $800^{\circ} \mathrm{C}$.

(2) The above-mentioned behaviour is closely related to two opposing processes in action at high temperature exposures. Process (1) is sintering and/or further geopolymarisation at high temperature and has an effect of increasing the strength. Process (2) is the damage due to thermal incompatibility.

(3) Ductility or brittleness of the mortar is a governing factor in the level of damage due to Process (2). This is found to be the overriding factor, regardless of the two types of fly ashes used with significantly different properties.

\section{Acknowledgements:}

The results presented in this paper are from a research project funded by Australian Research Council, Discovery Grant No. DP0664309. Authors would like to acknowledge the contributions from Dr Frank Collins, and the contributions from the laboratory staff Mr Long Goh and Mr Jeff Doddrell. 
Table 1 Composition of fly ash as determined by XRF (mass \%)

\begin{tabular}{lccccccccc}
\hline $\begin{array}{l}\text { Element as } \\
\text { oxide }\end{array}$ & $\mathrm{Al}_{2} \mathrm{O}_{3}$ & $\mathrm{SiO}_{2}$ & $\mathrm{CaO}$ & $\mathrm{Fe}_{2} \mathrm{O}_{3}$ & $\mathrm{~K}_{2} \mathrm{O}$ & $\mathrm{MgO}$ & $\mathrm{Na}_{2} \mathrm{O}$ & $\mathrm{SO}_{3}$ & $\begin{array}{l}\text { Loss on } \\
\text { ignition }\end{array}$ \\
\hline Ash A & 23.2 & 72.2 & 0.2 & 0.6 & 0.4 & 0.1 & 0.1 & 0.1 & 1.4 \\
Ash B & 30.6 & 48.4 & 2.7 & 12.1 & 0.3 & 1.3 & 0.2 & 0.3 & 1.7 \\
\hline
\end{tabular}

Table.2 The effect of Curing conditions on the initial compressive strength

\begin{tabular}{|c|c|c|c|c|c|c|c|c|c|c|}
\hline \multirow{3}{*}{ Specimen ID* } & \multicolumn{5}{|c|}{ Ash A } & \multicolumn{5}{|c|}{ Ash B } \\
\hline & $55 \mathrm{~W}$ & $60 \mathrm{~S}$ & $55 \mathrm{~W}$ & $60 \mathrm{~S}$ & $80 \mathrm{~S}$ & $60 \mathrm{~S} 2$ & $60 \mathrm{~S} 5$ & $55 \mathrm{~W}$ & $60 \mathrm{~S}$ & $60 \mathrm{~S}$ \\
\hline & 24 & 24 & 96 & 96 & 96 & & & 15 & 15 & 18 \\
\hline $\begin{array}{l}\text { Curing Temperature } \\
\left({ }^{\circ} \mathrm{C}\right)\end{array}$ & 55 & 60 & 55 & 60 & 80 & 60 & 60 & 55 & 60 & 60 \\
\hline Curing Time (h) & 24 & 24 & 96 & 96 & 96 & 2 & 5 & 15 & 15 & 18 \\
\hline $\begin{array}{l}\text { Compressive Strength } \\
(\mathrm{MPa}) * *\end{array}$ & 13 & 16 & 25 & 33 & 43 & 5 & 17 & 37 & 51 & 60 \\
\hline $\begin{array}{l}\text { Density before exposure } \\
\left(\mathrm{kg} / \mathrm{m}^{3}\right)\end{array}$ & 2065 & 2074 & 2165 & 2030 & 2108 & 2128 & 2134 & 2117 & 2108 & 2029 \\
\hline $\begin{array}{l}\text { Density after exposure } \\
\left(\mathrm{kg} / \mathrm{m}^{3}\right)\end{array}$ & 1963 & 1949 & 1882 & 1964 & 1898 & 1947 & 1946 & 1954 & 1938 & 1845 \\
\hline $\begin{array}{l}\text { * Specimens den } \\
\text { and cured in tl } \\
\text { same conditio } \\
\text { being cured in }\end{array}$ & $\mathrm{d} \mathrm{b}$ & $\mathrm{S}^{\prime \prime}$, & $\begin{array}{l}\text { ke } \\
\text { is d }\end{array}$ & $\mathrm{n}$ the & ould & nd $v$ & $\begin{array}{l}\text { pped } \\
\text { t and } \\
\text { full }\end{array}$ & $\begin{array}{l}\text { pla } \\
\text { rapp }\end{array}$ & $\begin{array}{l}\text { sheet } \\
\text { in the } \\
\text { while }\end{array}$ & \\
\hline
\end{tabular}




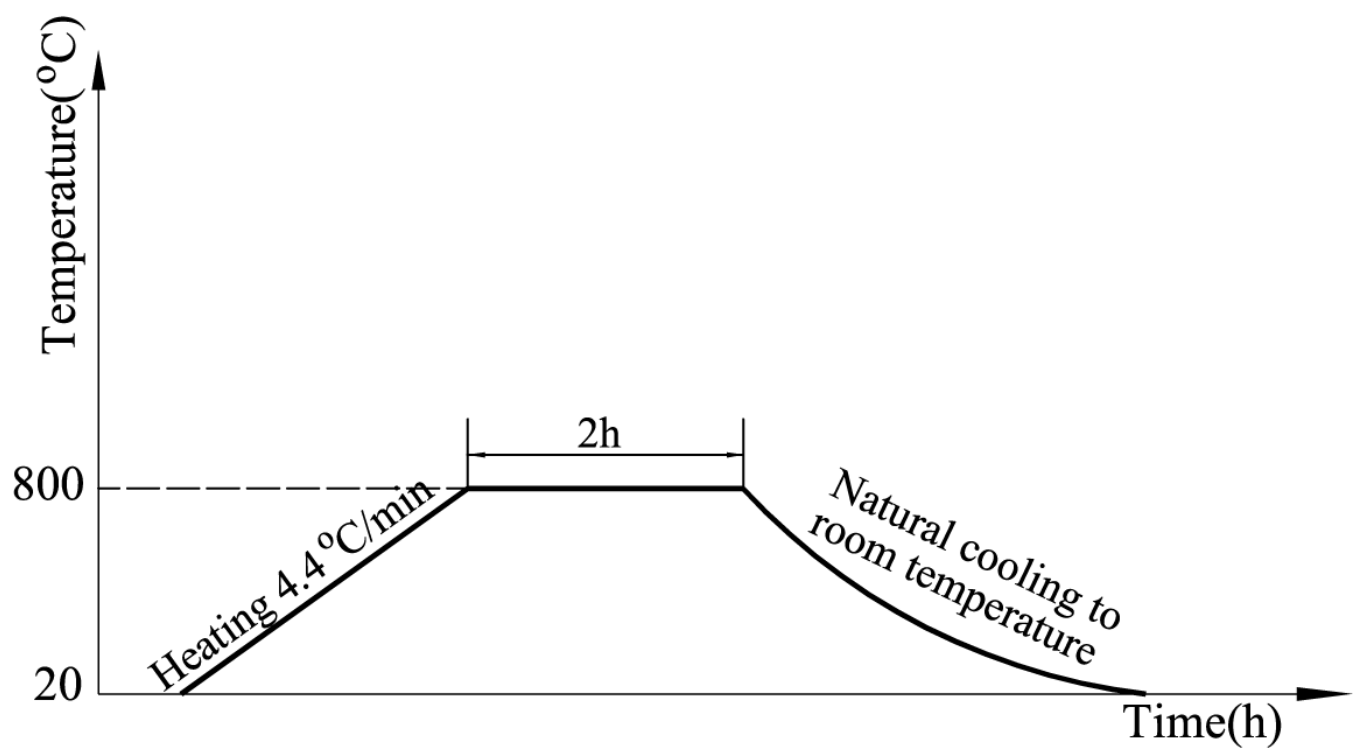

Fig.1 Elevated temperatures exposure regime

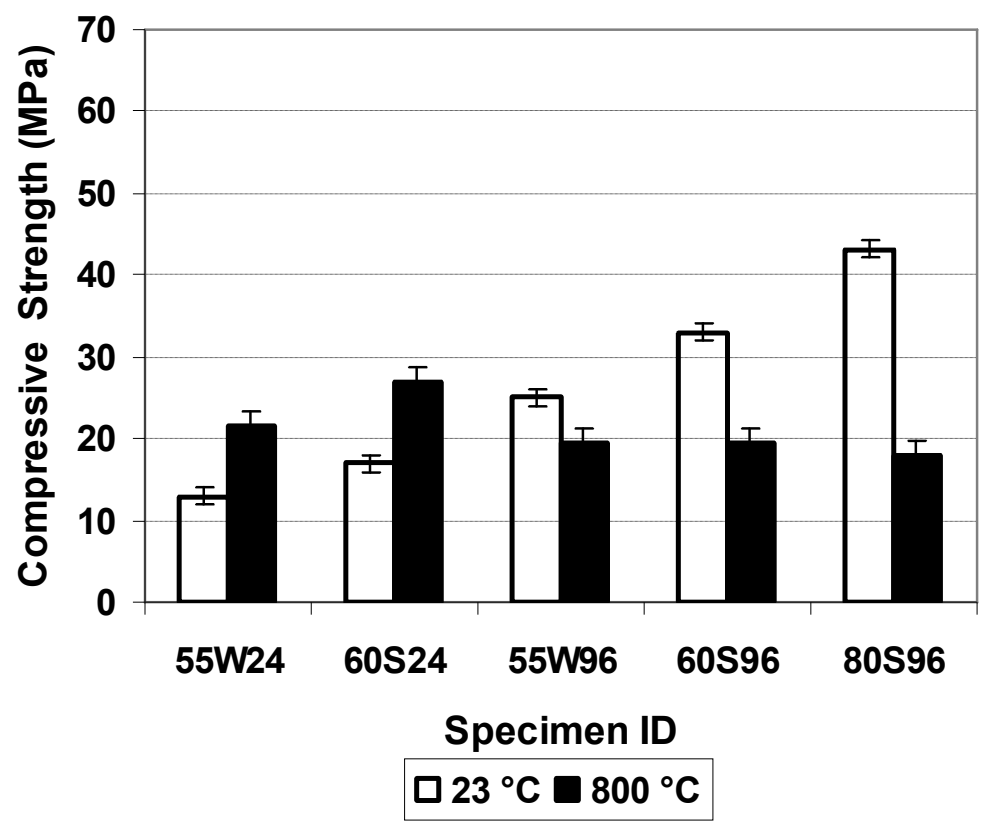

Fig.2 Effect of high temperature on compressive strength of specimens prepared using Ash A (Specimen ID details are given in Table 3) 


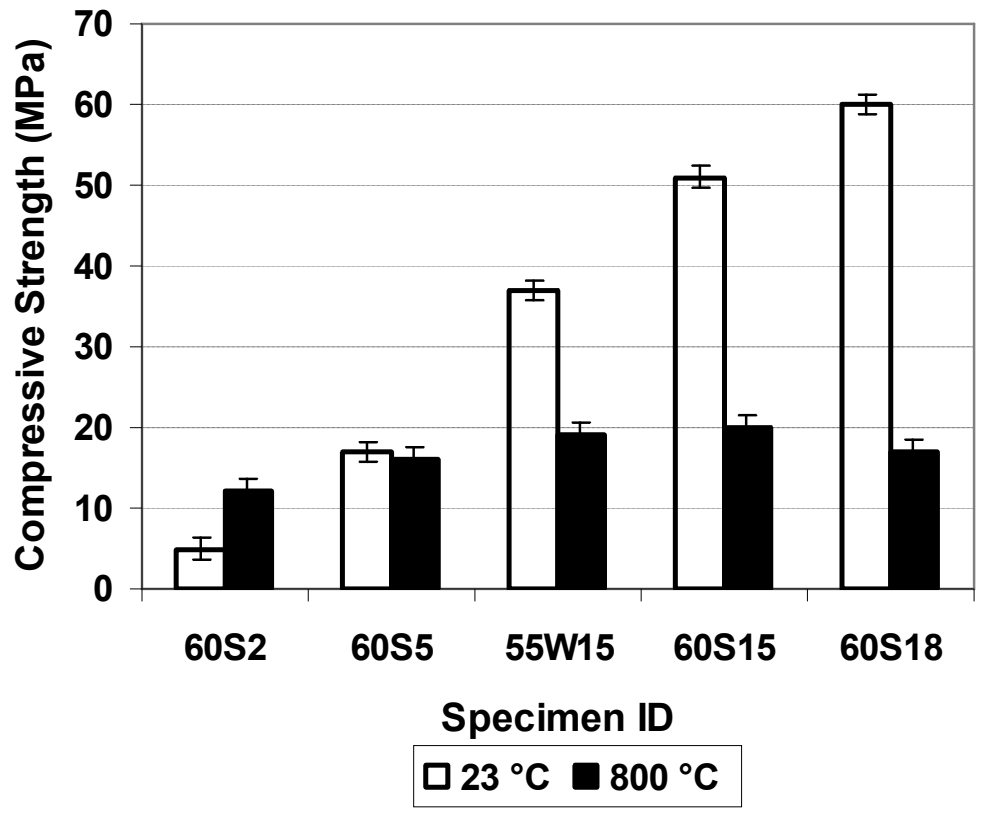

Fig.3 Effect of high temperature on compressive strength of specimens prepared using Ash B (Specimen ID details are shown in Table 3)

Thermogravimetric Analysis

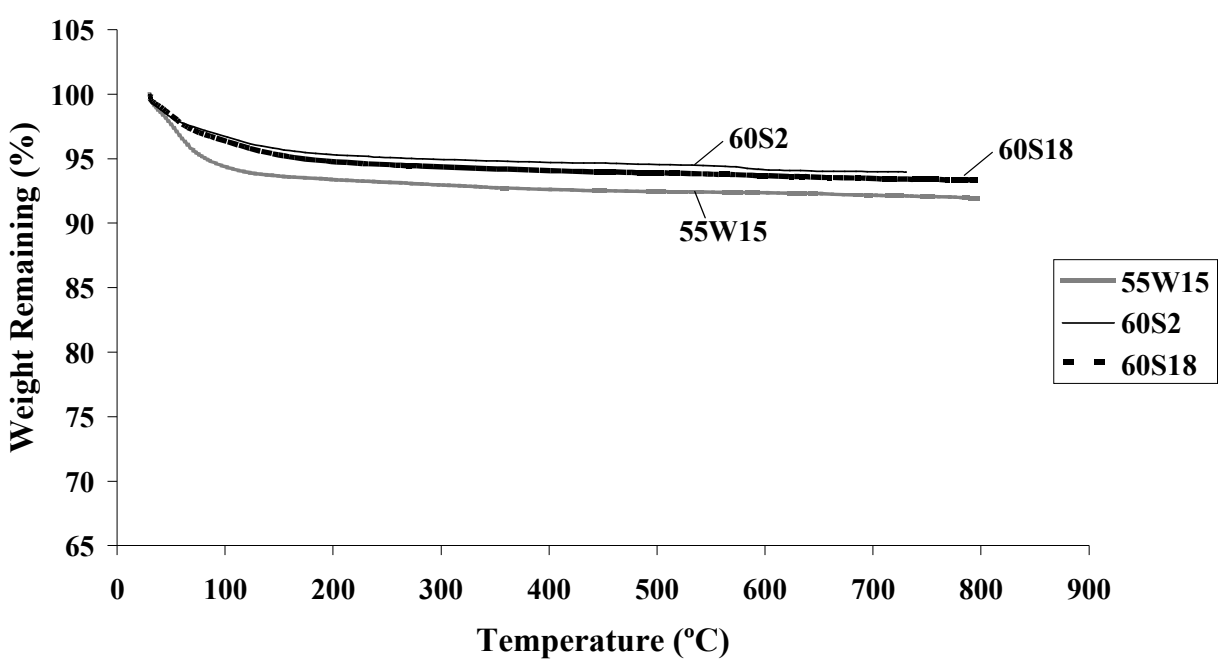

Fig.4 TGA curves 


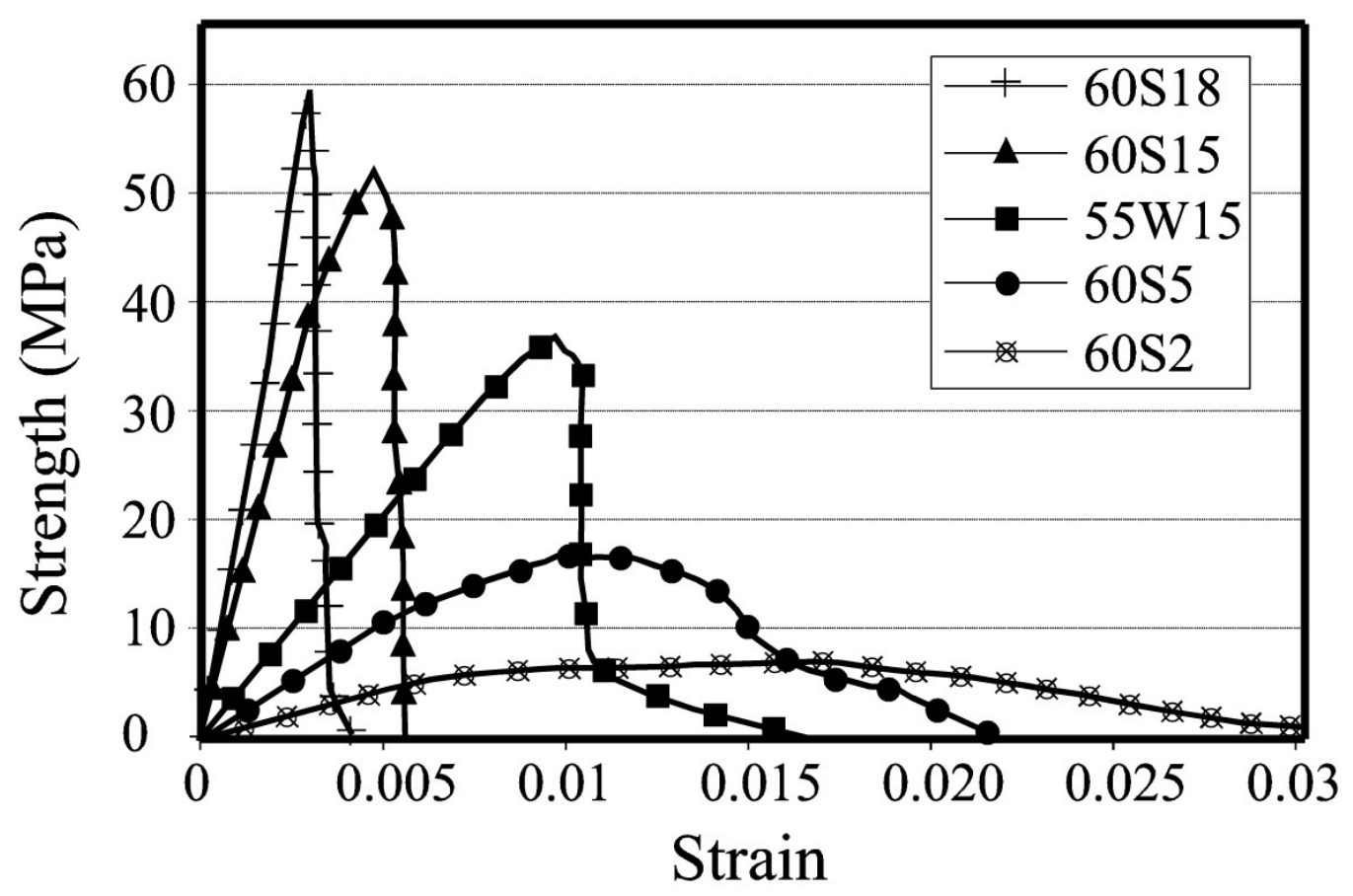

Fig.6 Stress-strain curve for specimens prepared using Ash B 


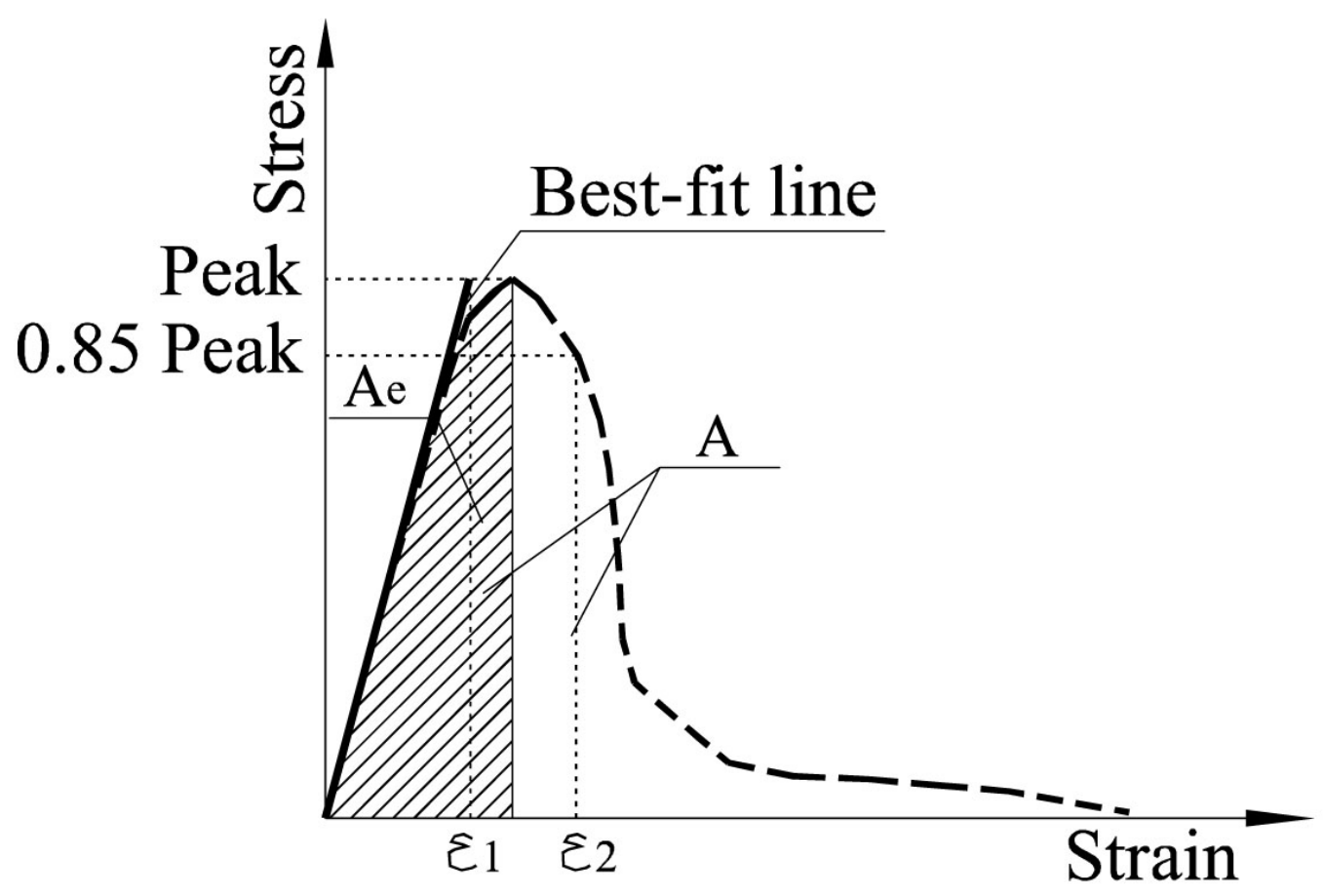

Fig.7 Definition of ductility used in this study

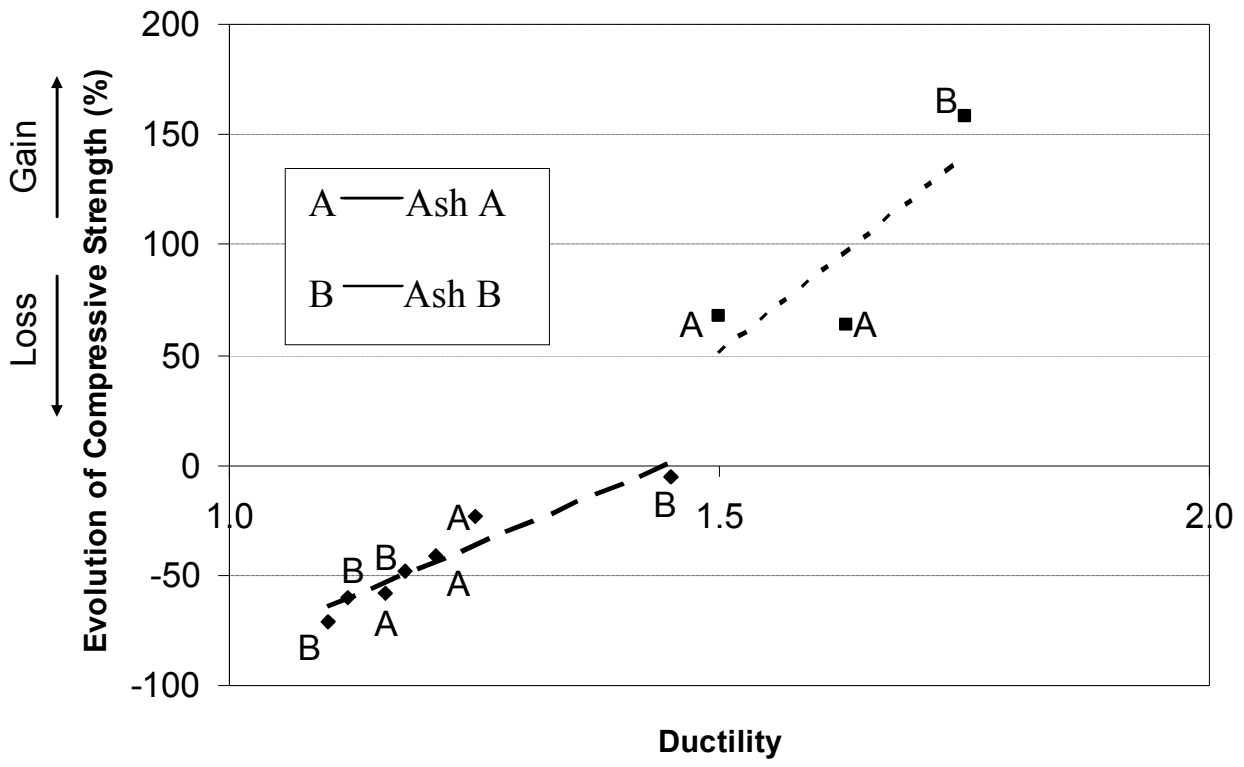

Fig.8 Effect of ductility on strength evolution when exposed to elevated temperature ( Definition of ductility by strain ratio ) 


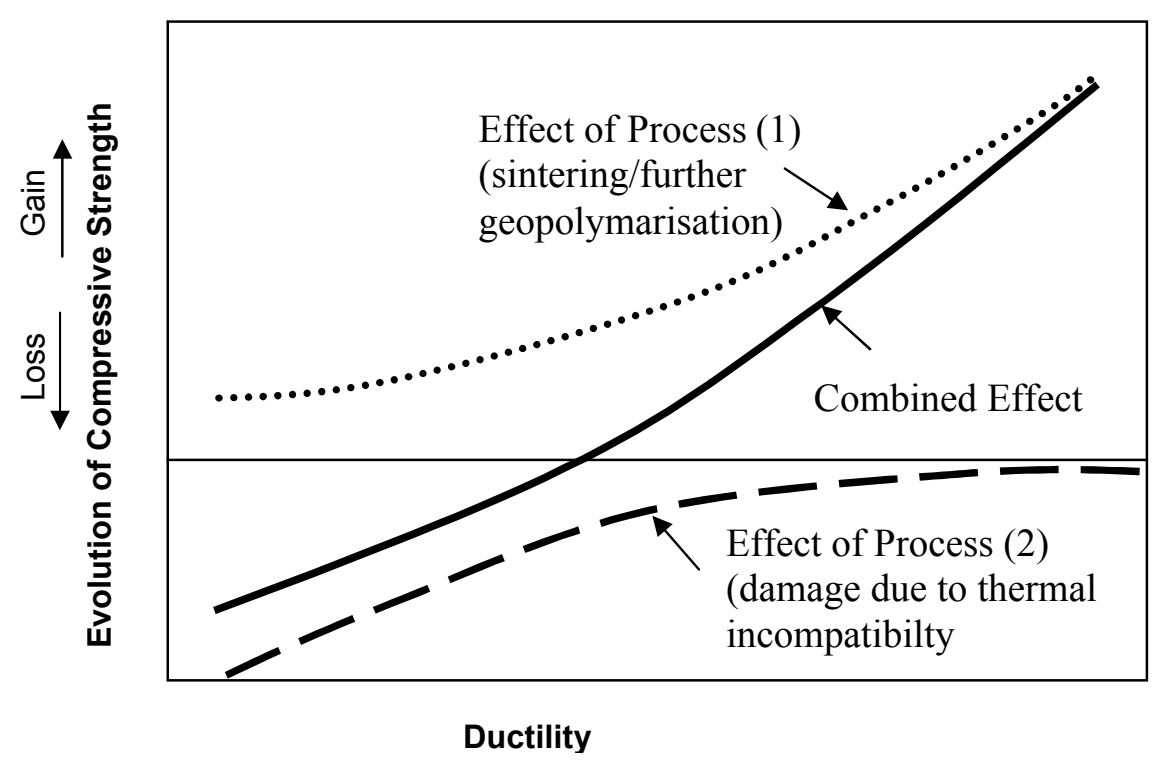

Fig.10 Schematic Diagram Describing the Two Parallel Processes in Geopolymer Mortars at Elevated Temperatures 


\section{References}

1. Davidovits J (1991) J Therm Anal 37(8):1633

2. Flower DJM, Sanjayan JG (2007) Int J Life Cycle Assess 12(5):282

3. Alonso S, Palomo (2001) Mater Lett 47:55

4. Fernandez-Jimenez A, Palomo A, Sobrados I, Sanz J (2006) Microporous Mesoporous Mater 91:111

5. Palomo A, Grutzeck MW, Blanco MT (1999) Cem Conrc Res 29:1323

6. Provis JL, Duxson P, van Deventer JSJ, Lukey GC (2005) Chem Eng Res Des 83(A7):853

7. Duxson P, Provis JL, Lukey GC, Mallicoat SW, Kriven WM, van Deventer JSJ (2005) Coll Surf .A 269: 7

8. Duxson P, Lukey GC, van Deventer JSJ (2006) J Non-Cryst Solids 352:5541

9. Hardjito D, Wallah SE, Sumajouw DMJ, Rangan BV (2004) ACI Mater J 101(6):467

10. Sumajouw DMJ, Hardjito D, Wallah SE, Rangan BV (2007) J Mater Sci 42(9):3124

11. Rangan BV (2003) Eng Aust 75(1):7

12. Hardjito D, Wallah SE, Sumajouw DMJ, Rangan BV (2002) J Aust Ceram Soc $38: 44$

13. Hardjito D, Wallah SE, Sumajouw DMJ, Rangan BV (2004) In:Proceedings of $18^{\text {th }}$ Australasian conference on the mechanics of structure \& materials. Perth

14. Rangan BV, Wallah SE, Sumajouw DMJ, Hardjito D (2006) Indian Concr J $80(6): 47$

15. Mendes A, Sanjayan JG, Collins FG (2008) Mater Struct 41(2):345

16. Khoury GA (1992) Mag Conrc Res 44 (12):291

17. Kong D, Sanjayan JG, Sagoe-Crentsil K (2007) Cem Conrc Res 37:1583

18. Bakharev T (2005) Cem Concr Res 35(6):1224

19. Dombrowski K, Buchwald A, Weil M (2007) J Mater Sci 42:3033

20. Poon CS, Shui ZH, Lam L (2004) Cem Conrc Res 34:2215

21. Nishida A, Yamazaki N (1995) In: Proceedings of the international conference on concrete under severe conditions. Sapporo, Japan, P 1140

22. Kalifa P, Chene G, Galle Ch (2001) Cem Concr Res 31:1487

23. Kong D, Sanjayan JG, Sagoe-Crentsil K (2008) J Mater Sci 43(3):824

24. Duxson P, Lukey GC, van Deventer JSJ(2007) J Mater Sci 42(8):56

25. Toutanji H, Balaguru P (1998) ASCE 10(2):52

26. van Jaarsveld JGS, van Deventer JSJ, Lukey GC (2003) Mater Lett 57:1272

27. Toumi B, Guemmadi, Z, Houari H, Chabil H (2007) In: Proceedings, Annaul Conference-Canadian Society for Civil Engineering. Yellowknife, NT, USA, P 987

28. Kristensen L, Hansen TC (1994) ACI Mater J 91(5):453

29. Rahier H, Simons W, Van Mele B, Biesemans M(1997) J Mater Sci 32(9):80

30. Kong D, Sanjayan JG (2008) Cem Concr Comp 30 (10):986 